This item was submitted to Loughborough's Research Repository by the author.

Items in Figshare are protected by copyright, with all rights reserved, unless otherwise indicated.

\title{
Project bank accounts: the second wave of security of payment?
}

PLEASE CITE THE PUBLISHED VERSION

http://dx.doi.org/10.1108/JFMPC-04-2017-0011

\section{PUBLISHER}

(c) Emerald Publishing Limited

\section{VERSION}

AM (Accepted Manuscript)

\section{PUBLISHER STATEMENT}

This work is made available according to the conditions of the Creative Commons Attribution-NonCommercialNoDerivatives 4.0 International (CC BY-NC-ND 4.0) licence. Full details of this licence are available at: https://creativecommons.org/licenses/by-nc-nd/4.0/

\section{LICENCE}

CC BY-NC-ND 4.0

\section{REPOSITORY RECORD}

Griffiths, Rachel, Wayne E. Lord, and Jeremy Coggins. 2019. "Project Bank Accounts: The Second Wave of Security of Payment?". figshare. https://hdl.handle.net/2134/25841. 


\title{
Project Bank Accounts: The Second Wave of Security of Payment?
}

\author{
Authors \\ Rachel Griffiths - North West Commercial Manager, Dwr Cymru Welsh Water. \\ Wayne Lord - Senior Lecturer, School of Civil and Building Engineering, Loughborough. \\ University \\ Dr Jeremy Coggins - Senior Lecturer, University of South Australia.
}

\section{Introduction}

The UK construction industry has long been plagued by poor payment practices recognised as long ago as 1964 (Banwell, 1964). The construction industry's payment problem (the "payment problem") is characterised by prolonged periods between supply of work/goods and payment, typically caused by late or delayed payment past the contractually agreed due date or by lengthy payment credit terms provided in the construction contract. The payment problem is by no means limited to the UK construction industry, being very much a common global phenomenon. ${ }^{\text {i }}$

The hierarchical, or tiered, structure of the industry's contractual framework makes it particularly susceptible to the payment problem. Contractors within the contracting chain receive payment funds from their principals above and are responsible for the delivery of those funds to contractors and suppliers below them in the chain. This payment structure encourages payment problems for two main reasons. Firstly, it means that, by virtue of a cascading 'domino effect', contractors and suppliers in the lower tiers are financially vulnerable to an insolvency or poor payment practice of a contractor higher up in the contracting chain. Secondly, it equips principal contractors, as providers of future revenue to their subcontractors, with a dominant bargaining position over the subordinate tier. As such, principal contractors are able to exert considerable commercial pressure on subcontractors and suppliers to extend prolonged trade credit terms in order to generate cash flow advantage and, thereby, cheap finance. This strategic management of cash flow, or 'cash farming' (Gyles 1992), enables principal contractors to enhance their profitability (Office of Government Commerce 2007: p.13).

A consultancy study carried out by the Office of Government Commerce (2007: p.14) of contractors and the construction supply chain found that all interviewees had first-hand experience of payment delays up to 90 days, and 60 day payments from clients were common with similar payment periods being reported in Australia (Senate Economics References Committee 2015: p.23; Collins 2012: p.77). This results in the perverse state of affairs whereby the smallest and most vulnerable construction businesses effectively end up financing the construction works, and bearing the greatest financial risks, on a construction project.

The payment problem is further accentuated by payment defaults which result due to high rates of business insolvency typically found within the construction industry. In 2015, for example, the construction sector had the highest corporate insolvency rate of any sector in England and Wales with 2,468 construction companies entering insolvency, representing $17 \%$ of all insolvencies in the UK (The Insolvency Service 2015). A similar state of affairs exists in Australia where construction accounted, on average, for $23 \%$ of all insolvencies between 2010/11 to 2013/14 (Senate Economic References Committee (2015: p.16). 
Over the past two decades, the UK has been recognised as one of the countries most active in trying to address the late construction payment situation (Albert 2002: p.277). Following recommendations by Sir Michael Latham (Latham, 1994) the UK led the way with respect to the introduction of construction payment and adjudication legislation ${ }^{\text {ii }}$. Since then similar legislation, all modelled to varying degrees on the UK legislation, has been passed in all the Australian states and territories, Singapore, Malaysia, New Zealand, and Ireland. ${ }^{\text {iii }}$ Although this legislative intervention has generally had a positive effect on payment culture, unethical and poor payment practices have continued in the UK (Price 2011: p.34; Ross and Williams 2013: pp.94-95; Wolstenholme 2009: p.19), particularly in the private sector where $84 \%$ of small businesses in the sector claim the private sector is most likely to make late payments (Federation of Small Businesses 2011).

Continued poor payment practices and high insolvency rates have led to the launch of numerous non-regulatory government initiatives in an attempt to further improve construction payment practices in the UK. Such initiatives have included, amongst others:

- the Prompt Payment Code, launched in 2008 by the then Department for Business Innovation and Skills, which establishes best practice principles for fair payment by code signatories when dealing with their suppliers;

- the Mystery Shopper Scheme, published in February 2012, which provides a clear, structured and direct route for suppliers to raise concerns about public procurement practice including late payment; and

- the Supply Chain Finance Initiative, rolled out by the UK Government in October 2012, under which large companies agree to help their supply chain access cheaper credit by communicating approval of invoices to financiers, thereby improving cash flow of smaller businesses.

(SEC Group, 2013)

A significant feature of many of the construction industry specific government initiatives has been the recommendation to use project bank accounts ("PBAs"), a type of payment trust mechanism which Davis (2012: p.24) acclaims as 'the most significant development' since Part II of the Housing Grants Construction and Regeneration Act. PBAs were initially recommended by the National Audit Office (2005) to yield public sector cost savings, and their use was endorsed by the Guide to best "Fair Payment" Practices issued by the Office of Government Commerce (OGC) in 2007. The Government Construction Board (GCB) decided in September 2009 that central government departments, their agencies and nondepartmental public bodies would move to a position where PBAs are adopted unless there are compelling reasons not to do so (Cabinet Office 2012a: p.3). This position was subsequently enshrined in statutory guidance accompanying the Public Contracts Regulations 2015. ${ }^{\text {iv }}$ The GCB also required that PBAs be used to at least Tier 3 in the hierarchical contracting chain on projects and for at least $80 \%$ of the value of work sub-contracted (Cabinet Office 2012a: p.3). In a briefing note issued in 2012, the Cabinet Office (2012b) promoted the use of PBAs proclaiming that "Government Construction Board members have committed, over the next three years, to deliver $£ 4$ bn worth of construction projects using PBAs." In January 2013, the Northern Ireland Executive announced that PBAs will be used in government construction contracts with an estimated value of $£ 1 \mathrm{~m}$ and over awarded by the Central Procurement Directorate on behalf of government departments. Furthermore, as from 31 October 2016, the Scottish Government has made the use of PBAs mandatory on public building projects with a value of over $£ 4.1$ million and civil engineering projects with 
a value of over $£ 10$ million. ${ }^{v}$ As such, PBAs have been used on many public sector contracts over the past decade (Davis, 2012).

Internationally, Australian governments are embarking upon a similar path with respect to the use of PBAs on public construction projects. New South Wales (NSW) and Western Australia (WA) have been trialling the use of PBAs on selected government sector contracts over the past two years. ${ }^{\text {vi }}$ The Queensland Government has announced its plans to introduce PBAs on all government projects between \$1 million and \$10 million as from 1 January 2018 and, significantly, on private sector construction projects over \$1 million as from January 2019 (Queensland Government 2017). Further, the trialling of PBAs on public construction projects has recently been the subject of public consultation in South Australia (Small Business Commissioner South Australia 2016). Additionally, the use of PBAs has been recommended at a federal level by the Senate Economics References Committee (2015: p.xxx) on construction projects where the Commonwealth's funding contribution exceeds $\$ 10$ million, and the current ongoing federal review into security of payment laws has raised statutory trusts as an issue for consultation (Murray 2017). In Western Australia, the first Australian jurisdiction to report on their PBA trials, the trial demonstrated the value that PBAs can offer in terms of improved certainty and timing of payment for subcontractors (Department of Finance (WA) 2016). Further, the Western Australian Minister (L'Estrange 2016) recently announced that PBAs will be applied to projects tendered by the Western Australia Building Management and Works unit from 30 ${ }^{\text {th }}$ September 2016 with a construction value of more than $\$ 1.5$ million, and involving one or more subcontractors. In Canada, the recent expert review of Ontario's Construction Lien Act recommended the trialling of individual project trust accounts for public sector projects over a period of two years (Reynolds and Vogel 2016: p.147).

The wholesale adoption of PBAs by the UK government, and the increasing trialling of PBAs by governments internationally, would appear to signal the arrival of a second wave of government initiated security of payment measures following the raft of payment and adjudication legislation enacted by many jurisdictions internationally. With the UK having pioneered the way with respect to both of these waves, albeit that the use of PBAs is still in its relative infancy, it is submitted that there are valuable lessons to be observed from the UK experience, especially by those international jurisdictions who have embarked upon the UK's path of enacting payment and adjudication legislation. As such, after considering literature relating to the operation of PBAs and resistance to their use, this paper presents the results of a questionnaire survey which aimed to discover the views of UK building contractors regarding: the nature and extent of payment problems that exist in the UK almost two decades after construction payment and adjudication legislation commenced; the effectiveness and impact of PBAs; and the barriers to the implementation of PBAs.

\section{What are PBAs?}

A PBA is a ring-fenced bank account from which payments are made directly and simultaneously to a lead contractor and members of the hierarchical contracting supply chain (Cabinet Office 2012a). The PBA may either be held in the sole name of the main contractor as trustee ('single authority' approach), or in the joint names of main contractor and client ('dual authority' approach). Under a PBA, the main contractor submits its progress payment to the client under the main contract showing a breakdown of payments to each of the suppliers. Once approved, the client pays the total amount of the progress payment into the PBA, and payment is then made out of the PBA to each of the suppliers with the dual agreement of the client and main contractor. Direct payment to the suppliers from a PBA 
enables the traditional lengthy contractual payment credit terms, which typically exist in subcontracts within the construction industry, to be bypassed ensuring a much quicker flow of funds down through the supply chain. Figure 1 illustrates the traditional contractual flow of funds versus the flow of funds via a PBA from the client to the supply chain.
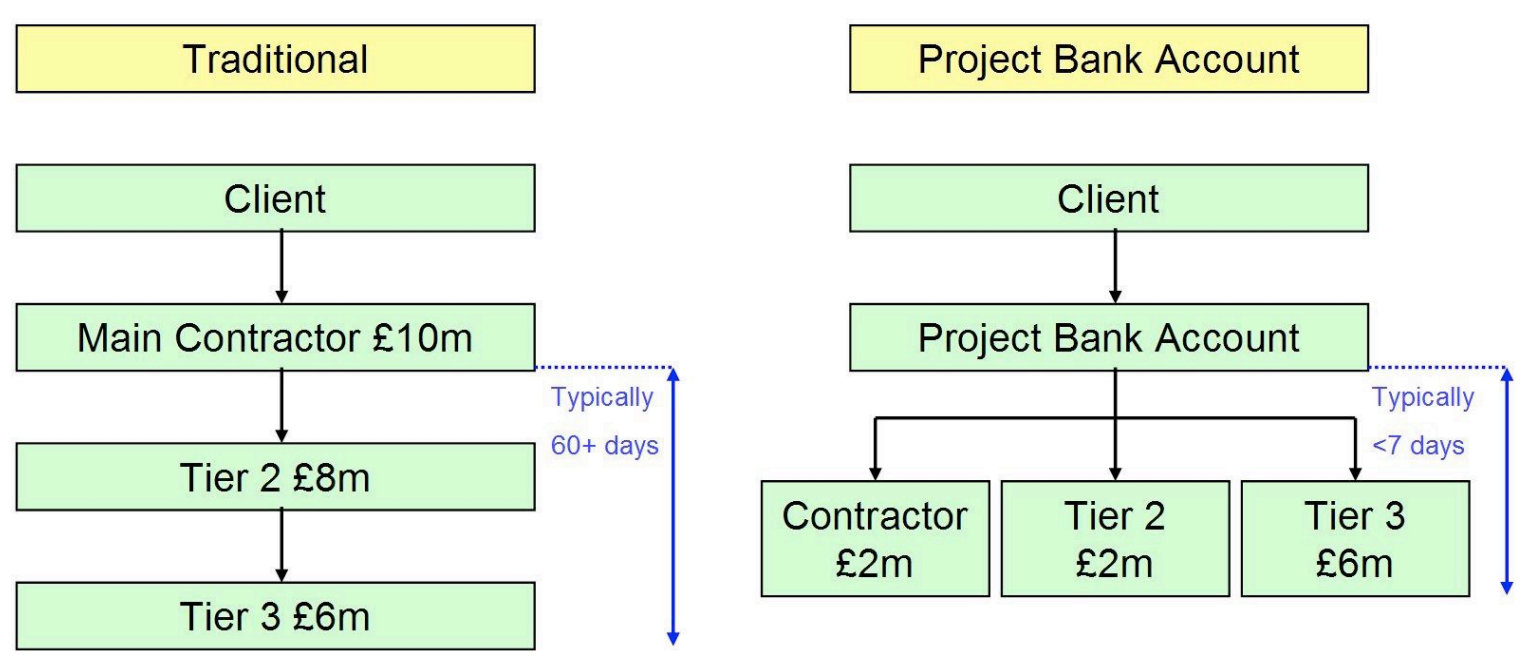

Figure 1: Flow of funds from client to supply chain (Biddell 2015: p.4)

A PBA has trust status by virtue of being linked to a trust deed, which sets out how the trustee's obligations with respect to operating the PBA and ensures that funds in the account are protected for the beneficiaries - i.e., those subcontractors and suppliers who have signed a joining deed (single authority) or deed of adherence (dual authority) - in the event of main contractor insolvency. In addition to faster payment and protection of funds against insolvency, PBAs offer transparency of payment flow throughout the supply chain.

\section{Resistance to the use of trust funds and PBAs}

The use of trust funds for payment is not a new proposition in the construction industry, having been recommended in statutory form by the Latham Report in the UK (Latham 1994: p.97), the Law Reform Commission of Western Australia (1998: p.51), and the Collins Report in NSW (Collins 2012: p.355). These recommendations, however, have not been acted upon and generally have been met with considerable resistance from employers and main contractors on the basis that, amongst other things, trust funds would add more cost to construction projects due to additional administrative burdens and the deprivation of working capital, or cash flow, to the main contractor who would have otherwise been able to use payment funds to service cash flow demands, secure finance and/or earn interest (Collins 2012: pp.309-316; Cole 2003: p.249).

Accordingly, despite several of the UK standard forms of construction contract having introduced PBA provisions to align with the OGC's fair payment guidelines (Office of Government Commerce 2007), ${ }^{\text {vii }}$ there has been reluctance amongst construction clients and main contractors to use PBAs (Price 2011: p.34; Kilgallon 2013), especially in the private sector. As Hughes-D'Aeth (2009) points out, PBAs confer no direct benefit on the employer or main contractor and, therefore, employers are only likely to adopt a PBA if it is easy to operate in practice.

A questionnaire survey of 61 construction industry participants carried out by Price (2011) found that barriers to the take up of PBAs included the cost of implementation, loss of cash 
flow benefits, and staff training. Other concerns cited by contractors with respect to the use of PBAs relate to contractual issues, including that PBAs cut across contractual provisions governing valuation and certification, they undermine the lead contractor's responsibility for managing the supply chain in accordance with the contract and they cause complications with pay less notices (Kilgallon 2013). These barriers and issues, however, have been addressed and generally refuted by the Cabinet Office (2012a: pp.4-6). Kilgallon (2013) identifies the main issue that contractors have with the use of PBAs as being the need for them to adjust their business models, because with PBAs they will no longer be able to benefit from the retention of their supply chain's money as many currently do.

It is of note, however, that the recent expert review of Ontario's Construction Lien Act (Reynolds and Vogel 2016) recommended that the New York statutory construction trust model, whereby a head contractor trustee may mix payment funds for multiple projects subject to strict bookkeeping practices, was at least in the short term preferable to individual PBAs as it would, amongst other things, not impose the same administrative burdens as would be required to maintain separate trust accounts (Reynolds and Vogel 2016: p.147). Having said this, the Ontario review did also recommend the trialling of individual project trust accounts for public sector projects over a period of two years (Reynolds and Vogel 2016: p.147).

With respect to the impact of PBA use on construction costs, the Cabinet Office (2012a: p.4) referred to a consultancy study reported by the Office of Government Commerce (2007: pp.13-23), which found that public sector clients could expect to save up to $2.5 \%$. The breakdown of this saving is shown in Table 1 (the table is reproduced from the report and the total seems to be rounded up from $2.4 \%$ to $2.5 \%$ ). Additionally, as the Cabinet Office (2012a: p.4) states, "The additional knock-on benefits of greater productivity and a reduction in construction disputes, and supply chain failures are difficult to quantify but they are likely to be substantial." There has, however, been doubt expressed by some as to whether such a saving is realistic - Hilder and Walshe (2013: p.23), for example, question if the OCG's figure considers whether the supply chain might add a premium due to an increased administrative burden associated, at least in the short term, with the use of PBAs.

\begin{tabular}{|c|c|}
\hline $\begin{array}{c}\text { Savings compared to base case } \\
\text { (traditional procurement): }\end{array}$ & $\begin{array}{c}\text { Using Project Bank } \\
\text { Account }\end{array}$ \\
\hline Sub-contract (total of all sub-contract) & $-0.1 \%$ \\
\hline Reduction for Cash Collection & $-2.1 \%$ \\
\hline Reduction for Cash Flow Risk Certainty & $-0.2 \%$ \\
\hline Reduction for Trade Indemnity Insurance & \\
\hline Lead Contract & $-0.2 \%$ \\
\hline Reduction for Cash Collection & $-0.8 \%$ \\
\hline $\begin{array}{c}\text { Reduction for Cash Flow Risk Certainty } \\
\text { Increased Profit to offset loss of cash } \\
\text { flow benefit } \\
\text { Total Impact on Project }\end{array}$ & $+1 \%$ \\
\cline { 2 - 2 }
\end{tabular}


Table 1: Benefit Analysis of PBAs (Office of Government Commerce 2007: p.18)

\section{Research Methodology}

With the use of PBAs in its infancy in the UK construction market, quantitative data from past projects was largely unavailable. Attempts were made to procure primary data from current, government agency driven, trial schemes but these attempts proved fruitless probably as a result of commercial sensitivities. The research therefore had little option but to rely on qualitative data by gathering perceptions of relevant parties in order to test the appropriateness of PBAs in practice. The gathering of opinions via questionnaire, distributed electronically, was considered the most appropriate especially as packages facilitate quantitative, statistical testing of the responses. Questionnaires were considered suitable to gather the data as the majority of the questions were closed. Furthermore, questionnaires allowed the collection of data quickly from a significant sample size across a wide geographical area and, due to their unilateral nature, assured respondents of anonymity thereby encouraging greater openness and honesty. The early questions were designed to be easy and straightforward to answer, gaining objective data about the respondent before following up with opinion-based questions. Although, as previously mentioned, the majority of the questions were closed, some questions permitted the respondent to provide comment. It was hoped that as the respondent grew in confidence with the survey, space for comments would provide the respondents with opportunity to include their own ideas in order to provide richer data.

The perceptive data were obtained by distributing a questionnaire survey. The population for the research was construction professionals working as full-time employees for either main (Tier 1) or specialist contractors (Tier 2 to 4$)^{\text {viii }}$. The questionnaire survey was distributed via an internet based survey tool, 'SurveyMonkey', to 84 construction professionals across a range of disciplines working within the UK construction industry. In addition to the 84 questionnaires sent directly to recipients via SurveyMonkey, a snowball sampling technique was adopted whereby the direct recipients of the questionnaire were asked to forward the questionnaire on to any appropriate contacts they knew working in construction contracting organisations. The sample for the distribution of the initial 84 questionnaires was drawn from the network of construction industry contacts that the lead author had developed whilst working at the offices of a major Tier 1 contractor. The direct sample was selected to ensure there was an even distribution of roles and tiers. Fifty-seven questionnaires were completed and returned, representing a response rate of $68 \%$ relative to the initial direct sample size of 84. One of the reasons for this unusually high response rate is likely due to the direct recipients of the questionnaire being drawn from the lead author's professional working network. Additionally, the figure of $68 \%$ is likely to be artificially high as the number of questionnaires passed on via the snowball sampling technique is unknown. Of the 57 questionnaires returned, $34(60 \%)$ represented Tier 1 construction professionals whilst 23 (40\%) represented Tier 2-4 construction professionals (the majority of these were probably Tier 2 based on the composition of the direct sample and distribution only - no further breakdown was considered necessary).

The first three survey questions related to the demographics of the respondents. The demographic profile of the questionnaire survey participants are shown in Table 2. 


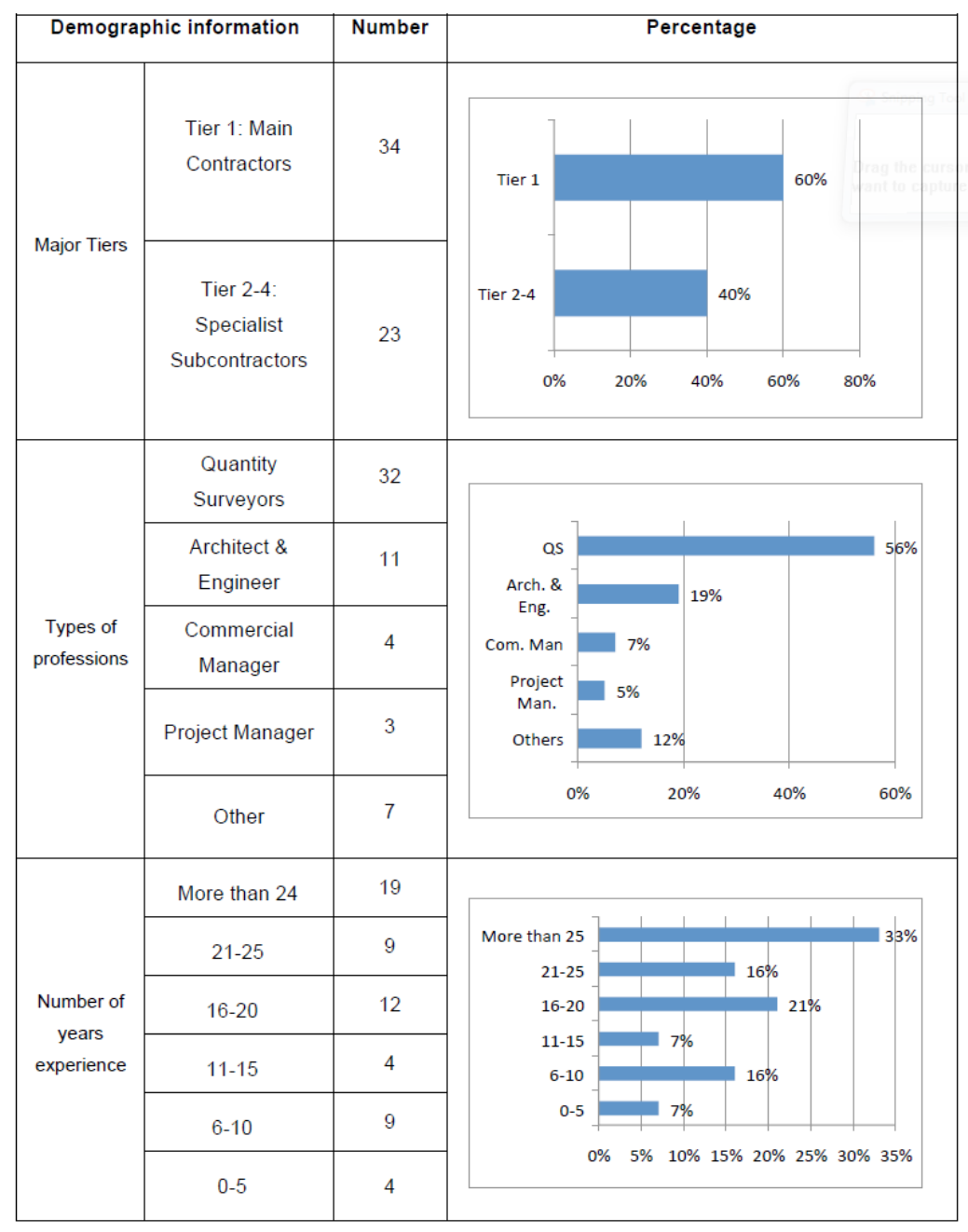

Table 2: Demographic profile of questionnaire survey participants

The rest of the questionnaire results are presented and analysed thematically below in accordance with the five sub-themes identified in the research objectives, namely: nature and extent of payment problems, sources of late payment, awareness and effectiveness of PBAs, enablers to the implementation of PBAs, and factors discouraging the use of PBAs.

\section{Analysis and Results}

\section{Nature and extent of payment problems}

Late payment was investigated using four questions relating to perceptions of late payment, compliance with contractual payment dates, effectiveness of legislation and risk allowance for delayed payment. The questions are set out below followed by a description of the respective survey responses.

There are inherent problems in the construction industry's payment practices. Do you agree? $(1=$ Yes, $2=$ No, $3=$ Possibly)

Seventy-five percent of participants indicated that payment problems were inherent in current payment practices. Comparison of averages indicated that a higher proportion of Tier 2-4 respondents (mean: 1.26) considered there to be a payment problem than Tier 1 respondents $($ mean $=1.47)$. 
Do you agree that current payment legislation is ineffective? $(1=$ Yes, $2=$ No, $3=$ Possibly)

A clear majority of respondents perceived the legislation as ineffective (Tier 1: $n=24(70 \%)$, Tier 2-4: $n=16(70 \%)$, Overall: $n=40(70 \%))$. Eighteen percent of all respondents disagreed that the legislation is ineffective, and the remaining $12 \%$ responded that the legislation was 'possibly' ineffective.

In your experience, what percentage of payment invoices would you estimate are settled on or before the final date for payment?

Figure 2 illustrates the percentage of invoices that respondents indicated were paid on or before the final date for payment. For statistical analysis purposes, a response of $0 \%$ to $20 \%$ was attributed a value of $1,21 \%$ to $40 \%$ a value of $2,41 \%$ to $60 \%$ a value of $3,61 \%$ to $80 \%$ a value of 4 , and $81 \%$ to $100 \%$ a value of 5 . A comparison of averages indicated that Tiers $2-4$ (mean: 2.83) estimated a higher incidence of late payment than Tier 1 contractors (mean: 3.09), although a $P$ two-tail value of 0.43 indicates the difference between the means of the two groups to be statistically insignificant.

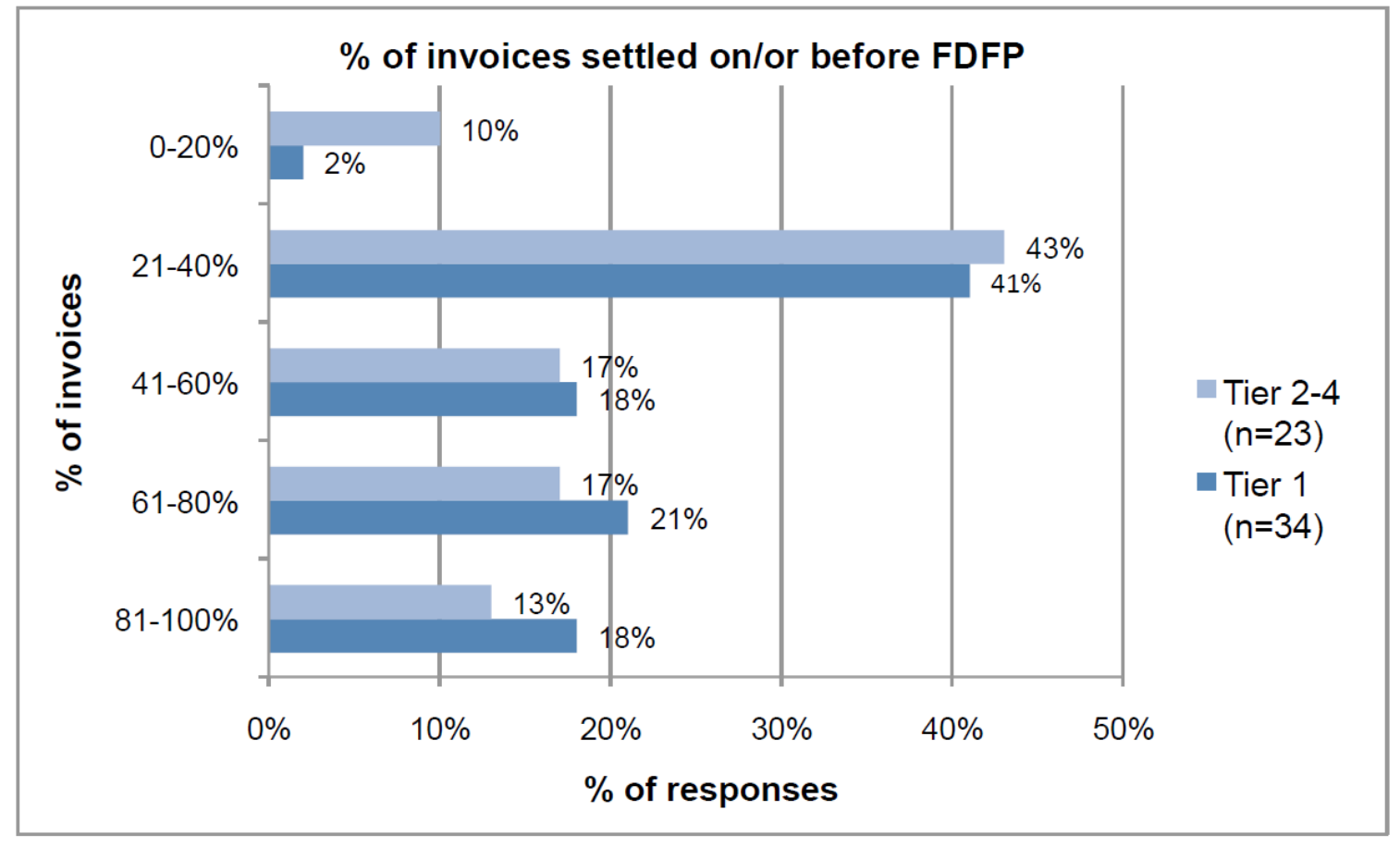

Figure 2: Percentage of invoices paid by the final date for payment

\section{What percentage of a tender is a typical risk allowance for late payment?}

To evaluate precautions taken by subcontractors, and to benchmark the accuracy of the OGC's estimated $2.5 \%$ PBA cost saving allowance for payment certainty, respondents were asked to indicate the percentage typically included within their quotations to insure against the potential risk of delayed payment. The mean risk allowance of all respondents was $2.27 \%$. The responses varied widely $(\mathrm{SD}=2.6)$, with a significant proportion of respondents (24 out of 54) indicating that they typically included no risk allowance at all. A comparison of averages indicated that Tier 2-4 contractors included a higher percentage for risk allowance $($ mean $=2.87 \%, \mathrm{SD}=2.03)$ than Tier 1 contractors (mean: $1.46 \%, \mathrm{SD}=2.83)$. A P 
two-tail value of 0.04 indicates the difference between the means of the two groups to be statistically significant. Numerous variables affecting risk allowance provision were commented on by participants, including " $0 \%$... to remain competitive in the current environment", "it depends on who we're doing work for", and "generally in the region of 1$2 \%$ depending on the client". Due to the wide variance of responses, further investigation is recommended.

\section{Sources of late payment}

Sources of late payment were investigated using two questions relating to primary causes of late payment, and deterrents to the pursuit of delayed payments using legislation. The questions are set out below followed by a description of the respective survey responses.

What do you consider to be the primary cause(s) of late payment?

Respondents were asked to indicate whether they considered six listed key causes of late payment to be primary causes of late payment in the construction industry by indicating either 'yes' or 'no' against each cause. For statistical analysis purposes, a 'yes' answer was attributed a value of 1 and a 'no' answer was attributed a value of 2. Multiple 'yes' or 'no' responses were permitted. As illustrated in Figure 3, 'strategic management of cash flow' (Tier 1 mean=1.35; Tier 2-4 mean $=1.35$, overall mean $=1.35$ ) and 'payment culture of the industry' $($ Tier 1 mean $=1.38$; Tier $2-4$ mean $=1.52$, overall mean $=1.44$ ) were the most commonly identified primary causes of late payment by the respondents.

It should be noted that industry culture was considered a far more prominent cause by Tier 1 respondents than Tier 2-4 respondents. Indeed, more Tier 2-4 respondents (21\%) indicated 'attitude of the payer' as a primary cause than 'payment culture of the industry' (15\%).

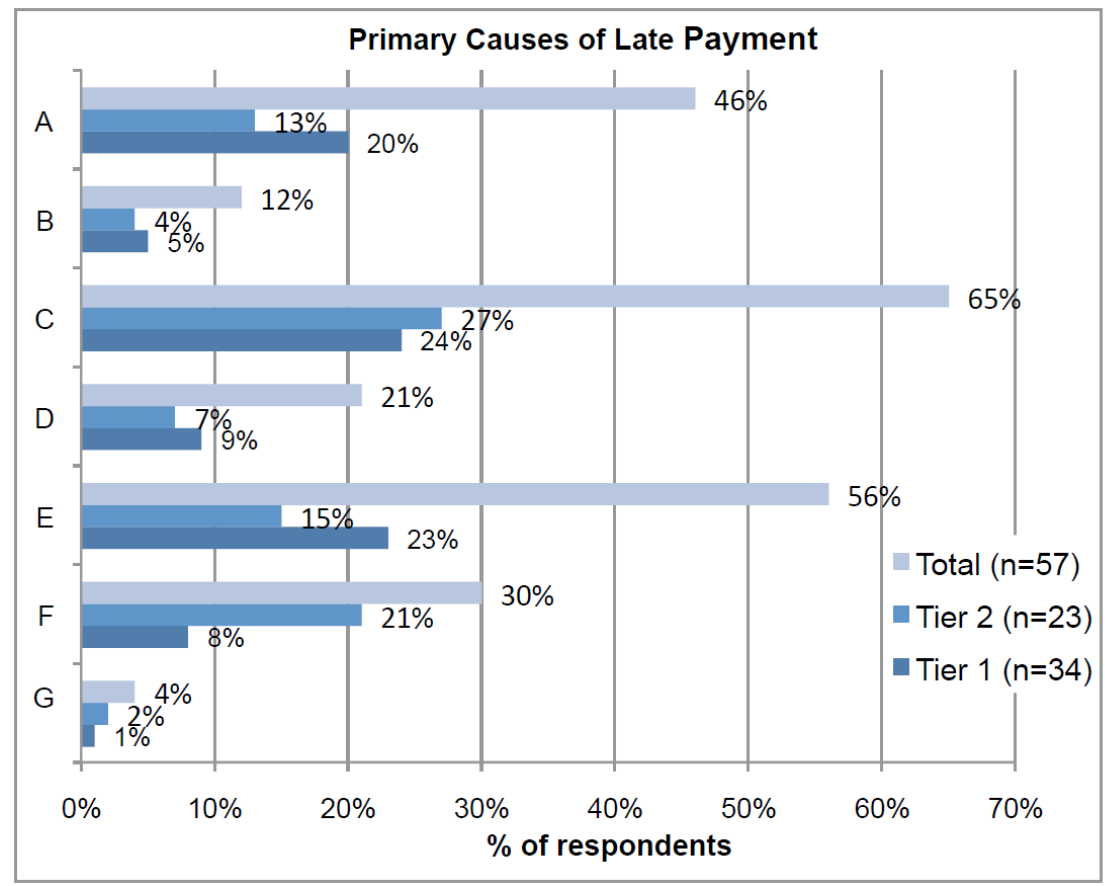

A:1.54 Administration Failure

B:1.88 Industry Structure

C:1.35 Strategic Man. of Cash Flow

D:1.79 Lack of Clarity / Understanding of Contractual terms

E:1.44 Payment culture of the industry

$\mathrm{F}: 1.70$ Attitude of the payer

G: Other

Figure 3: Primary cause(s) of late payment as perceived by respondents

What do you consider to be the main factor that prevents subcontractors from using legislation to pursue late payments? (1=legal expenses, $2=$ fear of reprisal, $3=$ =industry culture) 
Forty-four percent of Tier $1(n=15), 39 \%(n=9)$ of Tier $2-4$, and $42 \%(n=24)$ all respondents considered 'fear of reprisal' as the main factor preventing subcontractors from using the legislation. Thirty-two percent of Tier $1(n=11), 35 \%(n=8)$ of Tier $2-4$, and $34 \%(n=19)$ of all respondents considered 'legal expenses' as the main factor preventing subcontractors from using the legislation. Twenty-four percent $(n=8)$ of Tier $1,26 \%(n=6)$ of Tier $2-4$, and $25 \%$ $(\mathrm{n}=14)$ of all respondents considered 'the culture of the industry' as the primary deterrent to the use of legislation to pursue late payments

\section{Awareness and effectiveness of PBAs}

Awareness and effectiveness of PBAs was investigated using five questions relating to level of awareness of PBAs, comparison of PBAs with other payment initiatives, ability of PBAs to alleviate payment disputes, impact of PBAs on insolvencies, and the capacity of PBAs to deliver cost savings. The questions are set out below followed by a description of the respective survey responses.

To what extent are you familiar with the concept of project bank accounts?

Almost half $(44 \%, n=25)$ of all the respondents claimed to have an "understanding of the concept", with a further a third having a 'vague understanding' $(32 \%, n=18)$. Only one respondent $(2 \%)$ had actually experienced using PBAs.

How would you rate the following payment initiatives as measures to improve fair payment? $(1=$ not effective, $2=$ slight impact, $3=$ effective, $4=$ very effective $)$

Respondents were asked to rate the effectiveness, on a Likert-type scale of 1 to 4 , of four specific UK Government endorsed initiatives - Mystery Shopper Scheme, Prompt Payment Code, PBAs and Supply Chain Finance Initiative - in improving fair payment in the construction industry. Of all the schemes, PBAs were rated most highly (overall mean $=2.46$, Tier 1 mean $=2.50$, Tier $2-4$ mean $=2.41$ ) by all the respondents. The next highest rating scheme was the Prompt Payment Code (overall mean=1.75).

Could PBAs help the industry overcome its reputation for adversarial relationships, and reduce disputes? (yes, no, or potentially)

The overall responses to this question were generally inconclusive, although more respondents answered 'no' (36\%) than 'yes' $(22 \%)$. The proportion of respondents that answered 'yes' was equal as between Tier 1 (22\%) and Tier 2-4 (22\%) contractors. However, more Tier 1 contractors (40\%) by proportion answered 'no' than Tier $2-4$ contractors $(30 \%)$.

Do you believe that an increase in the use of project bank accounts would result in fewer insolvencies within the supply chain? $(1=$ yes, $2=$ no)

Of all respondents, 34\% did not believe, whereas $66 \%$ did believe that PBAs would result in fewer insolvencies. The proportion of yes/no responses was similar as between Tier 1 (mean= 1.36) and Tier 2-4 (mean=1.30) respondents.

The OCG claims that a PBA and fair payment can reduce a contract sum by $2.5 \%$. Do you agree? $(1=$ yes, $2=$ no, or $3=$ possibly $)$

Only one respondent $(2 \%)$ agreed that use of a PBA and fair payment could reduce a contract sum by $2.5 \%$., whereas $38 \%(n=13)$ of Tier $1,52 \%(n=12)$ of Tier $2-4$, and $44 \%(n=25)$ of all respondents disagreed that this level of saving was possible. 


\section{Enablers to the Implementation of PBAs}

Factors that might encourage and facilitate the use of PBAs were investigated using two questions relating to client influence and the primary advantages of PBAs. The questions are set out below followed by a description of the respective survey responses.

Do you think the Client is responsible for ensuring fair payment throughout the supply chain? (1=yes, $2=$ no, 3 = partially)

Forty-four percent $(n=15)$ of Tier $1,22 \%(n=5)$ of Tier $2-4$, and $35 \%(n=20)$ of all respondents believed that the client has a responsibility to ensure fair payment throughout the supply chain. Fifty-one percent of all respondents indicated that the client has a partial responsibility to do so.

How would you rate the advantages of using a project bank account?

Respondents were asked to rate the significance of five listed advantages potentially resulting from the use of PBAs by indicating each of the advantages to be either 'insignificant', 'no difference', or 'significant'. For statistical analysis purposes, an 'insignificant' answer was attributed a value of 1, a 'no difference' answer was attributed a value of 2 , and a 'significant' answer was attributed a value of 3 . Overall, the most highly rated advantages by the respondents were 'prompt payment' $($ Tier 1 mean $=2.71$, Tier $2-4$ mean $=2.74$, overall mean $=2.72$ ) and 'protection against contractor insolvency' (Tier 1 mean $=2.70$, Tier $2-4$ mean $=2.61$, overall mean $=2.66$ ). At the other end of the scale, 'cost savings' was considered to be the least significant advantage (Tier 1 mean $=2.00$, Tier $2-4$ mean $=1.78$, overall mean $=1.91)$.

\section{Factors discouraging use of $\mathrm{PB} A \mathrm{~s}$}

Factors that might discourage the use of PBAs were investigated using three questions relating to increased complexity of valuations, reduced incentive to tender and the barriers to the use of PBAs. The questions are set out below followed by a description of the respective survey responses.

Do you think valuations under the JCT and other forms of contract would be a problem when used with a PBA? $(1=$ yes, $2=$ no, $3=$ potentially $)$

Eleven percent of all respondents considered that the use of PBAs would cause a problem with respect to conducting valuations under the contract, $40 \%$ considered there would not be any problem, and $49 \%$ were undecided as to the issue. The apportionment of responses between the three options ('yes', 'no', and 'potentially') was similar as between Tier 1 $($ mean $=2.38)$ and Tier 2-4 (mean=2.39) respondents.

Would you tender for a project if it clearly stated that a PBA would be used? (1=yes, 2=no, $3=$ maybe)

Only $2 \%(n=1)$ of all respondents indicated they would be deterred from tendering on a project where a PBA would be used. $66 \%$ of all respondents indicated that they would not be deterred from tendering, with the remaining $32 \%$ indicating they would potentially be deterred. The apportionment of responses was similar as between Tier 1 and Tier 2-4 respondents, with $65 \%$ of Tier 1 , and $70 \%$ of Tier $2-4$, respondents answering 'yes'.

Please select what you consider as the main barrier to the use of Project Bank Accounts. Respondents were asked to select one out of a list of seven possible barriers to the use of PBAs. As illustrated in Figure 4, the most significant barriers were found to be 'resistance from main contractors' (Tier 1: $n=15$ (44\%), Tier 2-4: $n=13$ (57\%), Overall: $n=28(49 \%)$ ) 
'complex and confusing' (Tier 1: $n=7(21 \%)$, Tier 2-4: $n=5$ (22\%), Overall: $n=12(21 \%))$, and administrative demands (Tier 1: $n=7$ (21\%), Tier 2-4: $n=1(4 \%)$, Overall: $n=8(14 \%)$ ).

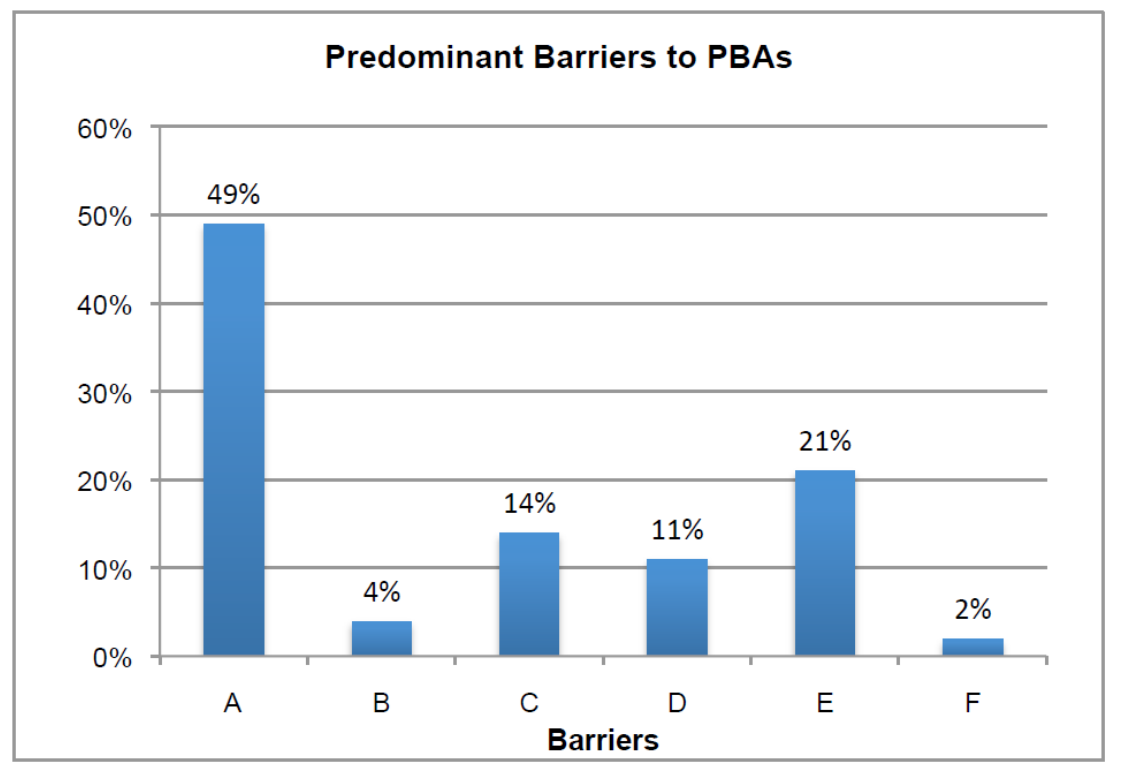

A: Resistance from main
contractor $(n=28)$
B: Problems resolving
contractual issues ( $n=2)$
C: Increased admin. $(n=8)$
D: Only Suited to Public
$\quad$ Sector ( $n=6)$
E Complex and Confusing
( $n=12$ )
F: Lack of Control ( $n=1)$

Figure 4: Main barriers to the use of PBAs

\section{Discussion}

The survey findings confirmed that, more than 15 years after the commencement of construction payment and adjudication legislation in the UK, a significant payment problem continues to abound in the construction industry. The perception that a payment problem exists was found to be stronger amongst those contractors below the first tier of the contracting chain. The primary cause of late payment within the construction industry was found to be strategic management of cash flow followed by payment culture of the industry. These findings support the notion that 'cash farming' (Gyles 1992) is endemic in the industry.

The continuing prevalence of a payment problem was reinforced by the finding that the vast majority of the survey respondents considered the payment and adjudication legislation to be ineffective. The primary reason subcontractors do not use the legislation was found to be due to fear or reprisal from their principals. ${ }^{\text {ix }}$

The survey findings as to the accuracy of the OCG's $2.5 \%$ project cost saving estimate due to use of a PBA are somewhat inconclusive On the one hand, some limited support for the OCG's estimate was observed on the basis that the respondents indicated a $2.27 \%$ mean tender allowance for risk of late payment. This finding, however, was tempered by the high standard deviation of the responses, and the fact that $45 \%$ of the respondents indicated that they included no allowance for late payment. On the other hand, the survey found that only $2 \%$ of respondents agreed that the OCG's project cost saving estimate was achievable as opposed to $44 \%$ of respondents who disagreed.

The survey indicates that awareness of PBAs amongst contractors is quite high with the vast majority of respondents either understanding, or having a vague understanding, of the concept of PBAs. The amount of contractors that have actually had experience of using a PBA within the sample was found to be very low. The degree to which this low experience 
rate is indicative of the wider industry, however, should be treated with caution given usage of PBAs will very much depend upon the exposure of a given sample of contractors to public sector work. It is suggested that the low PBA usage rate discovered in the survey is likely due to a limited exposure of the sample to medium to large public sector projects as well as a lack of PBA uptake on private sector construction projects. Going forward, the commitment of public sector clients (e.g., Defence Infrastructure Organisation, Ministry of Justice, Environment Agency, Highways Agency) to increasingly use PBAs is likely to further raise awareness and result in wider experience of use.

The survey found that contractors rate PBAs significantly higher than other recent major government initiatives with respect to encouraging fair payment. Further, the survey also found that a significant majority of contractors believe the use of PBAs would result in fewer insolvencies within the supply chain. Both of these findings are corroborated by the survey's finding that prompt payment and protection against contractor insolvency are the two most significant advantages of using PBAs.

The survey produced no conclusive finding to support the notion, as submitted by the Cabinet Office (2012a: p.4), that PBAs would reduce construction disputes. There was some consensus amongst the respondents, however, that PBAs would not cause a problem when used in conjunction with valuation and certification provisions in standard forms of contract. This supports the claim of the Cabinet Office (2012a: p.4) that PBAs do not cut across contractual provisions governing valuation and certification. Further, there was significant consensus that the use of PBAs would not deter contractors from submitting tenders.

The survey firmly indicated that contractors think that responsibility for ensuring fair payment throughout the supply chain rests, at least in part, with the project client. The survey also reinforced the notion that resistance from main contractors is viewed to be the biggest impediment to the use of PBAs, which is consistent with resistance to previous proposals to introduce trust accounts into the construction industry. Given that, as identified by HughesD'Aeth (2009), PBAs confer no direct benefit on employers or main contractors, these findings suggest that the adoption of PBAs by the private sector is likely to be slow.

\section{Conclusion}

This research found that, whilst approximately $40 \%$ of all payments to contractors are made on time, a significant proportion of payments, approximately $60 \%$, are late. To that extent, this study seems to demonstrate that, although construction payment and adjudication legislation has provided some improvement to the problem of late or undervalued payments in the UK, much more needs to be done - particularly with respect to addressing the two main reasons found in the research for late payment: "strategic management of cash flow" and "payment culture of the industry". The power still seems to rest with the payer, with payees being reluctant to rely on their statutory rights to pursue late payers for "fear of reprisal". PBAs break the culture of lead contractor 'control and command' by removing any advantage to main contractors in retaining payment funds, thereby neutralising the traditional construction contracting power imbalance. The general view is that PBAs are effective at both improving payment practices and reducing insolvencies.

The use of PBAs in the construction industry, however, is not without its challenges or limitations. The research seemed, on balance, to reject the UK Government's suggestion that PBAs generate cost savings to clients, although over half the respondents did, at least, concede that such savings were a possibility. The research also indicated that Tier 1 
contractors may be resistant to PBAs per se as a result of them being unable to strategically manage cash flow. With a paucity of quantitative research on the actual financial benefits of PBAs to clients and/or other stakeholders, it may be some time before they become mainstream on private sector projects. This raises the question as to whether the promotion and use of PBAs on public sector projects will eventually permeate to the private sector, or whether private sector adoption of PBAs will require legislation as is the case with payment trust accounts in some of the North American jurisdictions, such as New York and Toronto. The need for, and shape of, any such legislation in the UK is a matter for future consideration and further investigation once the impact of widespread use of PBAs on public sector projects has become apparent.

Another limitation of PBAs is that they cannot prevent head contractors from disputing payment claims in the supply chain in order to reduce payments. It may, however, be argued that the inability to utilise withheld cash should, at least, remove any incentive for main contractors to fabricate disputes in order to reduce progress payments. Further, under the UK Government Construction Board's PBA model, where PBAs should be used to Tier 3 and for at least $80 \%$ of the value of the subcontracted work, it could be argued that the "status quo" remains for those smaller firms in the lower tiers of the contracting supply chain and arguably those most in need of security of payment protection. Therefore even with PBAs, if the general payment culture remains unchanged, further bolstering of payment and adjudication legislation for specifically smaller payment claims may be necessary. ${ }^{\mathrm{x}}$

There is a need for continuing research into PBA usage and its impact upon the construction industry. The need for research in this area is important not just to the UK, but also to several other international jurisdictions that appear to be embarking upon a similar PBA path. Looking further ahead, if PBAs continue to prove their worth, it is suggested that other important issues for further investigation in order to optimise PBA effectiveness could include how PBAs interact with the different models of payment and adjudication legislation, and whether the use of PBAs should be mandated by legislation in the private sector as the Queensland Government plans to do. In the meantime, whilst PBAs may not be an instant panacea for the construction industry's payment problem, they do at first sight appear to introduce a much needed second wave to address the seeming ongoing lack of security of payment in the construction industry.

\footnotetext{
'See, for example, Cole 2003 (Australia); Wu, Kumaraswamy and Soo 2008 (China); Ramachandra and Rotimi 2011 (New Zealand); Che Munaaim, Mohd Danuri and Abdul-Rahman 2007 (Malaysia); Reynolds and Vogel 2016 (Ontario); Albert 2002 (European Union).

ii see Part II of The Housing Grants, Construction and Regeneration Act 1996 as amended by the Local Democracy, Economic Development and Construction Act 2009 Part 8 (LDEDC, 2009) and supplemented by the Late Payment of Commercial Debts (Interest) Act 1998 as amended in 2013.

iii Statutory construction adjudication is under parliamentary consideration in South Africa and Hong Kong and recommended for implementation in Ontario (Reynolds and Vogel 2016).

iv See Public Contracts Regulations 2015, Statutory guidance for contracting authorities and Suppliers on paying undisputed invoices in 30 days down the supply chain, at p.9.

${ }^{v}$ See Scottish Procurement Policy Note SPPN 10/16, $23^{\text {rd }}$ September 2016, Scottish Government.

${ }^{v i}$ See further, https://www.procurepoint.nsw.gov.au/before-you-buy/construction/project-bank-accounts; https://www.finance.wa.gov.au/cms/Building_Management_and_Works/New_Buildings/Project_bank_accou nts.aspx viewed on 23 Nov 2016.

vii E.g., JCT 2016 Project Bank Account Documentation; NEC3 Option Y(UK)1.
} 
viii $F$ or the purposes of this paper, a 'Tier 1' contractor is directly engaged by the client/developer, a 'Tier 2' contractor is a trade contractor engaged by the Tier 1 contractor, a "Tier 3 " contractor is a trade subcontractor engaged by a Tier 2 contractor and so on.

${ }^{\text {ix }}$ This correlates with similar findings in Australian research - see, for example, Brand and Uher (2010: 17).

${ }^{x}$ Such a model, which affords greater legislation protection to smaller contractors, was proposed by Coggins (2011). Furthermore, Queensland is the only jurisdiction to date to have introduced a dual payment/adjudication system which affords greater protection for smaller payment claims - see Building and Construction Industry Payments Act 2004 (Queensland).

\section{References}

Albert, J., 2002, Review of the effectiveness of European Community legislation in combating late payments, Implemented for European Commissions. 30-CE0039936/0092. pp 1-277.

Banwell, H., 1964, The Placing and Management of Contracts for Building and Civil Engineering Work, (The Banwell Report), London: HMSO.

Biddell, L., 2015, Implementation of Project Bank Accounts across Highways England, Highways England.

Brand, M. C., and Uher, T. E.,2010, "Follow-up empirical study of the performance of the New South Wales construction industry security of payment legislation." International Journal of Law in the Built Environment, 2(1).

Cabinet Office, 2012a, Government Construction, A Guide to the implementation of Project Bank Accounts (PBAs) in construction for government clients, 3 July 2012.

Cabinet Office, 2012b, Government Construction, Project Bank Accounts - Briefing document, viewed 17 Nov 2016, available at:

https://www.gov.uk/government/uploads/system/uploads/attachment_data/file/62117/ProjectBank-Accountsbriefing. pdf

Che Munaaim, M. E., Mohd Danuri, M. S., and Abdul-Rahman, H., 2007, "Is Late Or NonPayment A Significant Problem To Malaysian Contractors", Journal of Design and Built Environment, 3(1), 35-49. 
Coggins. J.,2011, "From Disparity to Harmonisation of Construction Industry Payment Legislation in Australia: a Proposal for a Dual Process of Adjudication based upon Size of Progress Payment Claim”, Australasian Journal of Construction Economics and Building, 11(2), pp. 34-59.

Cole, T.,2003, Final Report of the Royal Commission into the Building and Construction Industry, Commonwealth of Australia.

Collins B., 2012, Final Report of the Independent Inquiry into Construction Industry Insolvency in NSW, November 2012, NSW Government.

Department of Finance (WA), 2016, Project Bank Accounts, viewed 23 Nov 2016, available at:

https://www.finance.wa.gov.au/cms/Building_Management_and_Works/New_Buildings/Proj ect_bank_accounts.aspx

Department of Housing and Public Works (Q1d), 2015, Security of Payment Discussion Paper, December 2015, Queensland Government.

Davis, R., 2012. Project Bank Accounts, A paper presented to the Society of Construction Law at a meeting in London on the 6th March 2012. Leics. 175, pp 1-25.

Federation of Small Businesses, 2011, Late Payment, viewed 25 Nov 2016, available at: www.fsb.org.uk/LegacySitePath/policy/rpu/.../late\%20payment\%20july\%202011.pdf

Gyles, R.V.,1992, Report of the Hearings: Part 1, Royal Commission into Productivity in the Building Industry in New South Wales, Vol. 3, NSW State Government Publisher, Sydney.

Hilder, N., and Walshe, B., 2013, Prompt Payment in Construction Contracts: Project bank accounts in construction projects, Infra Read, Ashurst, (2), pp. 21-23.

Hughes-D'Aeth. J., 2009, JCT Project Bank Account documentation: do the payment provisions work?, viewed 9 Dec 2016, available at:

$\mathrm{http}$ //constructionblog.practicallaw.com/jct-project-bank-account-documentation-do-thepayment-provisions-work/

Kilgallon, B., 2013, "The late show: project bank accounts", RICS Construction Journal. April /May 2013.

Latham, M., 1994, Constructing the Team- The Final Report of the Government / Industry Review of Procurement Arrangements in the UK Construction Industry, (The Latham Report), London: HMSO.

Law Reform Commission of Western Australia, 1998, Financial Protection in the Building and Construction Industry - Report, Perth, WA.

L'Estrange, S., 2016, WA leads the way with project bank accounts, Minister's office - 6552 6900. 
Murray, J., 2017, Review of Security of Payments Laws: Issues Paper, Department of Employment, Australian Government.

National Audit Office, 2005, Improving Public Services through better construction, London: The Stationery Office.

Office of Government Commerce, 2007, Guide to Best 'Fair Payment' Practices, London: HMSO.

Office of Government Commerce, 2010. Making fair payment in construction a requirement in central government contracts, Information Note 2/2010. London: HMSO.

Price, R., 2011, Industry Structure: The problem of pay. Construction Research and Innovation Journal. 2(2), 34-38.

Queensland Building Services Authority (2010). Building and Construction Industry Payments Act 2004, Discussion Paper. Brisbane.

Queensland Government, 2017, Security of Payment, viewed 28 Feb 2017, available at: http://queenslandbuildingplan.engagementhq.com/security-of-payment

Ramachandra, T., and Rotimi, J.O., 2011, "The nature of payment problems in the New Zealand construction industry", Australasian Journal of Construction Economics and Building, 11 (2) 22-33.

Reynolds, B., and Vogel, S., 2016, Striking the Balance: Expert Review of Ontario's Construction Lien Act, Report prepared for the Ministry of the Attorney General and the Ministry of Economic Development, Employment and Infrastructure, Ontario.

Ross, A., and Williams, P., 2013, Financial Management in Construction Contracting. Chichester, West Sussex: John Wiley \& Sons.

SEC Group, 2013, Fair Payment in Construction Government Initiatives/Commitments 2006 to 2013, London: SEC Group, viewed 17 Nov 2016, available at:

http://www.secgroup.org.uk/Payments2.html

Senate Economics References Committee, 2015, 'I just want to be paid' - Insolvency in the Australian construction industry, December 2015, Commonwealth of Australia.

Small Business Commissioner South Australia, 2016, Proposed Changes to the Building and Construction Industry Security of Payment Act 2009 and Other Initiatives to Improve Payment to Subcontractors in the Building and Construction Industry, Consultation Paper June 2016, Government of South Australia.

The Insolvency Service, 2015, Insolvency Statistics - July to September 2016 (Q3 2016), UK Government, viewed 25 Nov 2016, available at:

https://www.gov.uk/government/statistics/insolvency-statistics-july-to-september-2016 
Wolstenholme, A., 2009, Never Waste a Good Crisis - A Review of Progress since Rethinking Construction and Thoughts for Our Future, Constructing Excellence in the Built Environment, London, UK.

Wu, J., Kumaraswamy, M., and Soo, G., 2008, "Payment Problems and Regulatory Responses in the Construction Industry: Mainland China Perspective", Journal of Professional Issues in Engineering Education and Practice, 134(4). 